\title{
Correction to: Preface to the Thematic Section: Mine Tailings: Problem or Opportunity? Towards a Combined Remediation and Resource Recovery Approach
}

\author{
Lieven Machiels ${ }^{1} \cdot$ Max Frenzel $^{2} \cdot$ Daniel Goldmann $^{3} \cdot$ Mirja Illikainen $^{4} \cdot$ Stephan Pfister $^{5}$
}

Published online: 27 December 2021

๑) The Minerals, Metals \& Materials Society 2021

\section{Correction to: \\ Journal of Sustainable Metallurgy (2021) 7:1440-1443 https://doi.org/10.1007/s40831-021-00468-7}

As a result of an error during the publication process, in-text reference citations in the first sentence under the heading "The Plombières Case-An Example of a Small-Scale Historical Tailing Site" and the first sentence under the heading "The Neves Corvo Case-An Example of a Large-Scale Present-Day Tailings Storage Facility" were incorrect in this article as originally published.

The original article has been corrected.

The original article can be found online at https://doi.org/10.1007/ s40831-021-00468-7.

Lieven Machiels

lieven.machiels@kuleuven.be

1 Department of Chemistry, KU Leuven, Celestijnenlaan 200F

Heverlee, box 2404, B-3001 Leuven, Belgium

2 Helmholtz Institute Freiberg for Resource Technology, Freiberg, Germany

3 Department of Mineral and Waste Processing, Institute of Mineral and Waste Processing, Waste Disposal and Geomechanics, Clausthal University of Technology, Walther-Nernst-Str. 9, 38678 Clausthal-Zellerfeld, Germany

4 Fiber and Particle Engineering Research Unit, University of Oulu, P.O. Box 4300, 90570 Oulu, Finland

5 Group for Ecological Systems Design, Institute of Environmental Engineering, ETH Zurich, John-vonNeumann-Weg 9, Zurich, Switzerland
Publisher's Note Springer Nature remains neutral with regard to jurisdictional claims in published maps and institutional affiliations. 